\title{
Comparison of self-and other-report of symptoms of autism and comorbid psychopathology in adults with autism spectrum disorder
}

\author{
Amanda M Pear1*, Erin M Edwards and Michael J Murray \\ Division of Autism Services, Penn State Hershey, 500 University Drive Hershey, PA 17033, USA
}

\begin{abstract}
While the presentation of autism-related symptoms is variable across individuals with ASD, there is growing evidence that many of these symptoms may be further complicated or exacerbated by comorbid symptoms of psychopathology. Some individuals with ASD may also have difficulty reflecting and reporting on their own behavioral and emotional symptoms, which can interfere with diagnosis and treatment. The current study compared self- and other-ratings of the behavior of 47 young adults with ASD in the home environment, to identify areas of rater agreement and discrepancy across symptoms of both ASD and general pathology. For ASD symptoms, nominated reporters rated the participant's behavior as significantly more impaired regarding social communication symptoms, but no significant difference was found for restricted and repetitive behavior. For symptoms of psychopathology, only attention problems, depression problems, avoidant personality problems, and total problems were reported by others as significantly higher when compared to self-report. While this provides increased confidence for assessing most comorbid symptoms of psychopathology via one reporter, results suggest obtaining collateral reports for ASD symptoms may be important for comprehensive assessment. The results from this study may inform the future of the clinical field regarding the use of a more efficient assessment of individuals with ASD's behavior and comorbid psychopathology.
\end{abstract}

\section{Introduction}

Recent estimates indicate that 1 in 68 individuals meet criteria for ASD [1]. Social communication and social interaction deficits, as well as restricted and repetitive behaviors represent the two core symptoms of Autism Spectrum Disorder [2]. Research has shown significant differences across a variety of social communication deficits and restricted and repetitive behaviors when comparing individuals with ASD and typically developing individuals. Younger children with ASD often fail to naturally develop and demonstrate joint attention, an early form of social interaction typically observed between a parent and toddler [3,4]. Continued difficulties as the child develops are observed in reduced number of social initiations and reciprocity in conversation and sustained conversation skills, compared to typically developing school aged children $[5,6]$. Finally, several studies have demonstrated reduced ability in individuals with ASD to recognize and correctly interpret emotional states from facial affect [7], vocal affect, [8], and video vignettes of interactions [9].

Though many interventions to improve symptoms of ASD have focused on children [10-12], there is evidence that these difficulties persist with age [13-16]. As adults, individuals with autism are faced with an even greater variety of social interactions and complexities, as well as the expectation of greater independence in navigating them. With limited ability to interpret social communication, adults with ASD may in turn interact with others in ways that may be perceived as incongruent, indifferent, or offensive in situations where the expected response would involve an empathetic or reciprocal reaction.

\section{Assessment of core deficits of ASD}

Constantino et al. [17,18] referred to the communication and social interactions skills deficits in individuals with ASD collectively as reciprocal social behavior (RSB). RSB "requires an individual to be cognizant of the emotional cues of others, to interpret those cues appropriately, to respond appropriately to what he or she interprets, and to be motivated to engage in social interactions with others" [19]. As a means to assess RBS, Constantino and Gruber developed the Social Responsiveness Scale, Second Edition [18]. The SRS 2 measures RSB in addition to restrictive/stereotyped behavior and interests, across four domains, two composite scores, and a total score for both self- and other-report of symptoms. The SRS 2 has been demonstrated to distinguish individuals with ASD (from those without or those with other psychiatric conditions), as well as provide a range of scores that correspond to severity of impairment [18].

Greater severity of impairment of RSB has been shown to be significantly associated with poorer outcomes across peer relationships [20], romantic relationships [21], adaptive behavior skills [22], and overall outcome measures [23] for adults. Similarly, deficits in RSB have been hypothesized to contribute to the high rates of unemployment and under-employment of adults with disabilities [24,25]. Social communication and perception skills are critical for interviewing, working with co-workers, understanding social norms in a work

Correspondence to: Amanda M. Pearl, PhD, Assistant Professor of Psychiatry, Division of Autism Services, Penn State Hershey, 500 University Drive Hershey, PA 17033, USA, E-mail: apearl@pennstatehealth.psu.edu

Key words: adults, autism spectrum disorder, psychopathology

Received: November 26, 2016; Accepted: December 24, 2016; Published: December 28, 2016 
setting and maintaining a positive relationship with supervisors. In a qualitative study by Hurlbutt et al. [26], adults, with ASD reported experiencing more challenges with navigating the social expectations of the workplace than with the work-tasks themselves. Limitations on employment, social relationships, and adaptive behavior place adults with ASD at high risk for isolation and poor quality of life.

\section{Comorbid psychopathology}

While the presentation of autism-related symptoms is unique across individuals with ASD, there is growing evidence that many of these symptoms may be complicated or exacerbated by comorbid psychiatric diagnoses. In samples of children with ASD, studies have found that the children scored within the clinical range for least one other comorbid psychiatric disorder for up to $95 \%[27,28]$ in a sample that had been referred for treatment [29]. More specifically, many children with ASD meet the criteria for disruptive behavior disorders [e.g., attention-deficit/hyperactivity disorder (ADHD), oppositional defiant disorder (ODD)], anxiety, or affective disorders [30,31]. Recent studies with adults with ASD suggest that many of these comorbidities continue or develop in adulthood as well [32-34] prompting more interest in how best to assess and treat potential comorbid pathologies, discriminant from ASD symptoms, in clinical practice [35].

Among internalizing disorders, comorbid anxiety disorders in individuals with ASD have been most extensively studied [35] and co-occur at higher rates in the ASD population than in populations without ASD symptoms [36,37] and non-ASD psychiatric referred populations [34]. Mood or depressive disorders also are shown to co-occur in individuals with autism at greater rates than the general population $[28,32]$. In a sample of adults with an ASD (diagnosed with DSM-IV criteria including Autistic Disorder, Aspergers' Disorder or Pervasive Developmental Disorder), 50\% and 53\% met the criteria for anxiety and mood disorder respectively [33]. Joshi et al. [34] found similar percentages of lifetime comorbidities in referred adults with ASD.

Despite the previous exclusion of ADHD diagnosis comorbid with ASD in the DSM-IV, recent research, and the reversal of this exclusion in DSM-V, suggest that the comorbidity exists in relatively high rates and is relevant to study to determine effective treatment $[28,38,39]$. Criteria for ADHD diagnosis has been found among $43 \%$ of adults with ASD. Similarly, Joshi et al. [34] found $42 \%$ of adults with ASD in a referred population to have a comorbid ADHD diagnosis, with $63 \%$ of the sample reporting having the diagnosis at some point in their lifetime. Though ADHD has shown the highest rates of comorbidity as a separate DSM diagnosis, an abundance of literature exists describing other challenging externalizing behavior or disruptive behavior disorders common among those diagnosed with autism [40,41]. Studies report a range of $27 \%$ to $42 \%$ of children to have a comorbid diagnosis of Oppositional Defiant Disorder (ODD), while rates of comorbid Conduct Disorder in children with ASD have been found to be quite low ranging from $3 \%$ to $10 \%$.

\section{Cross-ratings of behavior}

In order to maximize construct validity while at the same time minimizing measurement error, both researchers and clinicians often attempt to secure multiple measures of behavior as a means to identify the true score on a variable of interest $[42,43]$. In spite of this wellknown recommendation for practice, securing reports of behavior on multiple measures from various methods is not always feasible, particularly when assessing for diagnoses of ASD in adults. Therefore, it is important to identify whom to ask about which behavior of interest, particularly if asking only one person will suffice.

This dilemma is pertinent for individuals working with adults diagnosed with ASD who may present with difficulty reporting on their own behavioral and emotional symptoms. Often it has been assumed that all individuals with ASD are unable to report on their symptoms; however, research is limited and individuals who work with this population often find that some individuals with ASD are able to accurately report on their symptoms and emotional states. Similarly, several autism symptom scales that provide multiple reporter versions have reported generally good correlation between self- and otherreport $[44,45]$. Among children and adolescents, at least three studies have found that children tend to report fewer autistic traits or greater social competency skills than their parents rate them as having [46-48]. However, Knott et al. [47] did report a positive correlation between child and parents scores, but found the parent scores indicated a greater impact of symptoms (e.g., in severity, frequency or rate) than the child self-report of symptoms. More recently, De la Marche et al. [49] found that among adults, although inter-informant agreement was lower for the adults with ASD than adults without ASD, the difference was not significant. Therefore, they concluded that adults with ASD were not an unreliable source of reported symptoms. With an aging ASD population, there is an increasing demand for effective assessments of adults with an ASD diagnosis. Across many mental health assessments with adults, there is a heavy reliance on self-reported data. However, there appears to be an insufficient amount of research about discrepancies in reports of behavior by multiple informants, chiefly in the population of individuals with ASD [50,51].

The comparison of ratings across reporters has been wellstudied in neurotypical children and adolescents. Achenbach et al. [52] conducted a meta-analysis of 119 studies in which they found that different informants' ratings of emotional, social, or behavioral problems in children are incongruent. However, it has been found that the environment and context in which the information is based upon predicts the size of the informant discrepancies [53]. More specifically, ratings across reporters and environments (e.g., teacher at school compared to parent at home) were more discrepant than ratings across reporters in the same environment e.g., mother and father at home [52,53]. However, results from a study by Pearl et al. [50] examining concurrence of parent-report of behavior for adolescents with ASD showed high to moderate correspondence between mother and father ratings, deviating from past studies in typically-developing populations [52,54-56]. These results suggested that within the ASD population under situational constraints, one parent's report alone could suffice when rating the specific behaviors.

More recently, a meta-analysis was conducted examining the validity of self-report of symptoms of psychopathology in neurotypical adults in comparison to collateral reports of behavior [42]. It was found that there were on average modest correlations between self- and other-report of behavioral problems on different versions of the same questionnaire (e.g., 0.44 for externalizing symptoms, 0.43 for internalizing symptoms). The correlations were somewhat lower when different versions of questionnaires assessing similar psychological symptoms were compared. However, it was noted that this area of research is lacking and that more specific analysis of the correlation between self- and other-report of behavioral and emotional symptoms needs to be conducted in the future [43]. It is unclear if these relationships would be replicated within a sample of adults with ASD. 


\section{Current study}

The current study was designed to compare self- and other-ratings of young adults with ASD's behavior in the home environment. Specifically, this study examined differences between self-report and an elected reporter's ratings of symptoms of ASD, as well as general psychopathology in young adults with ASD. We expected that there would be significant differences between raters on both ASD symptoms and comorbid symptoms of general psychopathology, with more significant differences between raters in ASD symptoms. More specifically, it was hypothesized that individuals would rate their ASD symptoms and symptoms of general psychopathology lower than nominated reporters.

\section{Materials and methods}

\section{Participants}

Data was collected from 47 adults with ASD between the ages of 18- and 35-years-old who were enrolled in a larger study to determine the effectiveness of a social skills intervention. All data included in this study were collected at baseline prior to any intervention. Table 1 for descriptive statistics. The mean age of participants was 22.83 years $(\mathrm{SD}=4.17)$. The majority of participants were male, non-minority, and not married. Seventy percent of participants reported living with immediate or extended family. The majority of participants reported that they were either employed for wages or were a full-time student (60\%). Finally, the mean number of years of education for participants was 13.61 years $(\mathrm{SD}=1.99)$. The Kaufman Brief Intelligence Test, Second Edition [57] was used as a screener for inclusion for the larger study. Inclusion criteria for the larger study was a Verbal IQ of 70 or above. The mean composite IQ for the current participants was 99.09 $(\mathrm{SD}=20.07)$ and ranged from 54 to 138 . All participants were screened for and met criteria for the ability to self-report on their symptoms of ASD and general psychopathology.

\section{Procedure}

The participants in this study were part of a larger clinical trial examining the effectiveness of a social skills training program with peer modeling for young adults diagnosed with an ASD. Upon receiving a signed consent form allowing data to be used for research purposes, participants completed the Social Responsiveness Scale, Second Edition (SRS - 2) [18] and the Achenbach Self-Report Form (ASR; 58). Each participant was asked to nominate a reporter who was "someone they felt knew them well" for at least six months prior to the time of data collection. The same reporter completed both the SRS - 2 [18] and the Achenbach Adult Behavior Checklist [58].

\section{Measures}

Social Responsiveness Scale, Second Edition (SRS - 2): The

Table 1. Descriptive Statistics.

\begin{tabular}{|l|c|}
\hline & M (SD) or \% \\
\hline Age & $22.83(4.17)$ \\
\hline Gender (Female, Male) & $79 / 21 \%$ \\
\hline Ethnicity (Non-minority, Minority, Other) & $80 / 11 / 9 \%$ \\
\hline Marital status (Single, Dual) & $96 / 4 \%$ \\
\hline Living situation (With Family, Without Family)* & $70 / 30 \%$ \\
\hline Occupational status (Working/Student, Not working) & $60 / 40 \%$ \\
\hline Education (Years) & $13.61(1.99)$ \\
\hline IQ Composite & $98.55(20.04)$ \\
\hline *N = 27 & \\
\hline
\end{tabular}

SRS - 2 measures the severity of autism spectrum symptoms either by self-report or as observed by another adult informant, often a caregiver, family member, close friend, or significant other, in the target individual's natural setting (e.g., home, workplace, school). The SRS - 2 measures social impairment as a continuous construct, conceptualizing symptoms related to ASD as continuous, rather than a dichotomous (indicative of diagnosis or not) construct. The SRS - 2 consists of 65 items rated on a Likert scale, which ranges from 1 (not true) to 4 (almost always true). Four treatment subscales assessing social communication were included in the present analyses: social awareness, social cognition, social communication, and social motivation. Both the Social Communication Index and the Restricted and Repetitive Behavior Index, as well as the SRS - 2 Total Score were also included. Empirical examinations of the SRS - 2 indicate that it demonstrates adequate reliability and validity $[18,59]$.

Achenbach adult forms \& profiles: The Achenbach System of Empirical Based Assessments (ASEBA) includes assessments for adults ages 18- to 59-years-old which examines areas of behavioral, emotional, and social concern. Two versions of this assessment are available: a selfreport form (Self-Report Form) and a collateral report form (Adult Behavior Checklist). The forms include 126 items rated on a threepoint Likert scale of 0 (not true) to 2 (very true or often true). Both the Self-Report Form and Adult Behavior Checklist include syndrome scales and DSM-oriented scales which assess patterns of symptoms of psychopathology. Finally, both forms include overall scores for internalizing, externalizing, and total problems. The Self-Report Form and Adult Behavior Checklist have been found to demonstrate adequate reliability and validity [58].

Kaufman Brief Intelligence Test, Second Edition: The KBIT 2 is a brief assessment of intelligence for individuals between the ages of 4 - and 90-years-old. The KBIT 2 provides estimates for verbal (crystallized) and nonverbal (fluid) ability, as well as an overall IQ composite score, which reflects a measure of overall intelligence. The KBIT 2 has been found to demonstrate good reliability and validity [57].

\section{Methods}

All analyses were completed using SPSS 23. A priori a significance level of $\alpha=0.05$ was employed for all statistical tests. First, both Pearson and Intraclass Correlation (ICC) analyses were completed to assess for the significance of the relationship between raters on all variables. Subsequently, a comparison of informant rating was conducted using the method outlined by De Los Reyes et al. [53] to calculate standardized difference scores. The use of standardized scores as opposed to raw scores allows for more consistent estimates among informant discrepancies. Standardized difference scores were calculated by converting each informant's rating to a $z$-score and then subtracting the self-report standardized rating from the other-report standardized rating on the same variable.

\section{Results}

\section{Preliminary analyses}

Of the original sample of $56,84 \%$ of participants completed both assessments and had complete data from an elected reporter. Missing data were addressed by listwise deletion, which resulted in an effective sample size of 47 . Patterns of missingness were examined and it was found that the data were not missing at random. Missing data was not significantly related to any demographic variables; however, there were significant patterns of missing data related to the elected reporter's rating of the participant's symptoms of avoidant personality $(r=-.28$, 
$p<.05)$. Participants with missing data were rated as having more symptoms of avoidant personality problems. Therefore, imputation of missing values may not be the most appropriate and the remaining sample size was still sufficient to proceed with the analysis.

Data were analyzed to detect non-normal distributions. Both skewness and kurtosis parameters for each subscale were investigated. Upon examination of these parameters, significant skewness and kurtosis was detected. There is no agreement on what is an acceptable level of non-normality as judged by univariate skewness or kurtosis; however, simulation work has suggested that values greater than 2.0 may indicate moderate non-normality [60]. Given the average skewness $(M=1.97)$ and kurtosis $(M=1.18)$ in the dataset, as well as the fact that maximum likelihood estimation is reasonably robust under conditions of significant skewness, no transformation of the data was conducted prior to analyses and normality was assumed [61].

\section{Correlation analyses}

ASD symptoms: The Pearson correlations between participants and his/her nominated reporter on the social motivation $(\mathrm{r}=.39, p<$ .01) subscale were significant. ICCs between participants and his/her nominated reporter were significant for social cognition (ICC $=.37$, $p<.05$ ) and social motivation (ICC $=.57, p<.01$; Table 2 ). The ICCs for social awareness, social communication, restricted and repetitive behaviors, the Social Communication Index, and Total SRS - 2 were not significant.

Psychopathology symptoms: The majority of subscales on the Achenbach ratings scales were significantly correlated for the ICC and Pearson correlations for both the general subscales, as well as for the DSM-oriented subscales (Table 3). The only exceptions were

Table 2. SRS - 2: Degree of relationship between informants.

\begin{tabular}{|l|c|c|}
\hline Scale & Intraclass Correlation & Pearson Correlation \\
\hline Awareness & .36 & .22 \\
\hline Cognition & $.37 *$ & .23 \\
\hline Communication & .37 & .22 \\
\hline Motivation & $.57 * *$ & $.39 * *$ \\
\hline RRB & .22 & .12 \\
\hline SCI & .26 & .15 \\
\hline Total & .23 & .13 \\
\hline$* \boldsymbol{p}<. \mathbf{0 5} ; * \boldsymbol{p}<.01$ & & \\
\hline
\end{tabular}

Table 3. Achenbach: Degree of relationship between informants.

\begin{tabular}{|l|l|l|}
\hline Scale & Intra class Correlation & Pearson Correlation \\
\hline Anxious/Depressed & $.65^{* * *}$ & $.49^{* *}$ \\
\hline Withdrawn & $.40^{*}$ & .25 \\
\hline Somatic Complaints & $.82^{* * *}$ & $.69^{* *}$ \\
\hline Thought Problems & $.44 *$ & .28 \\
\hline Attention Problems & $.65^{* * *}$ & $.48^{* *}$ \\
\hline Aggressive Behavior & $.82^{* * *}$ & $.70^{* *}$ \\
\hline Rule-Breaking Behavior & $.60^{* *}$ & $.43^{* *}$ \\
\hline Intrusive & $.74 * * *$ & $.59^{* *}$ \\
\hline Internalizing Problems & $.67 * * *$ & $.53^{* *}$ \\
\hline Externalizing Problems & $.73 * * *$ & $.60^{* *}$ \\
\hline Total Problems & $.64 * * *$ & $.49^{* *}$ \\
\hline Depressive Problems & $.63 * *$ & $.46^{* *}$ \\
\hline Anxiety Problems & $.62 * *$ & $.45^{* *}$ \\
\hline Somatic Problems & $.83^{* * *}$ & $.72^{* *}$ \\
\hline Avoidant Personality Problems & $.62 * *$ & $.46^{* *}$ \\
\hline AD/H Problems & $.45^{*}$ & $.31^{*}$ \\
\hline Antisocial Personality Problems & $.77^{* * *}$ & $.64^{* *}$ \\
\hline$* p<.05, * * p .01, * * * p<.001$ & & \\
\hline
\end{tabular}

the Pearson correlations for the Withdrawn and Thought Problems subscales, which were not significantly correlated between informants. The highest correlations between informants were on the Somatic Complaints/Somatic Problems subscales and the Aggressive Behavior subscale suggesting the most agreement between informants in these areas of concern.

\section{Comparisons of informant ratings}

ASD symptoms: There were significant differences between participants' ratings of their own behavior and their nominated reporters' rating of their behavior on the SRS - 2 on all subscales except for Restricted and Repetitive Behavior (Table 4). On all subscales, nominated reporters rated the participant's behavior as more impaired. The effect sizes for these differences were in the small to medium size range (Cohen's $d$ range $=0.29$ to 0.57 ) and were the largest for social communication.

Psychopathology symptoms: Out of 17 subscales on the Achenbach ratings scales, only four subscales were found to be significantly different between self- and other-report of the participant's behavior (Table 5). Attention Problems and Total Problems, as well as the DSM-oriented scales Depressive Problems and Avoidant Personality Problems were found to be significantly different $(p<.05 ; p<.01$ for Avoidant Personality Problems), with the nominated reporter endorsing more impairment in these areas than the self-report of participants. The effect size for these differences were between small and medium (Cohen's $d$ range $=0.29$ to 0.44 ) .

\section{Post hoc moderator analyses}

Given the significant differences between raters on several subscales on both the SRS 2 and the Achenbach rating scales, post hoc exploratory moderator analyses were conducted to determine if any variables predicted differences in ratings of behavior between informants. Standardized difference scores for each subscale found to be significantly discrepant between reporters were used as the dependent measures in regression analyses testing all demographic variables as possible moderators. No demographic variables were significant moderators for the variables of interest.

\section{Discussion}

In the current study, young adults with ASD were asked to report on their own symptoms of ASD, as well as symptoms of comorbid psychopathology. Additionally, each participant was asked to nominate a reporter to rate the participant's symptoms of ASD and psychopathology in the home environment. It was anticipated that there would be significant differences between raters on both ASD symptoms and symptoms of general psychopathology, with more significant differences on ASD symptoms.

Table 4. $S R S-2$ : Significance of difference between informants.

\begin{tabular}{|l|c|c|c|c|c|c|}
\hline \multicolumn{2}{|c|}{ Self } & \multicolumn{2}{c|}{ Nominated Reporter } & & \\
\hline Scale & $M$ & $S D$ & $M$ & $S D$ & $t$ & Cohen's $d$ \\
\hline Awareness & 59.48 & 10.53 & 63.36 & 10.69 & $2.19^{*}$ & .37 \\
\hline Cognition & 62.66 & 10.41 & 66.32 & 10.96 & $2.06^{*}$ & .34 \\
\hline Communication & 63.20 & 9.22 & 68.28 & 8.62 & $3.35^{* *}$ & .57 \\
\hline Motivation & 64.04 & 10.75 & 68.04 & 10.46 & $2.53^{*}$ & .38 \\
\hline RRB & 65.46 & 11.86 & 68.80 & 11.35 & 1.62 & .29 \\
\hline SCI & 64.04 & 9.90 & 68.55 & 8.93 & $2.75^{* *}$ & .48 \\
\hline Total & 64.64 & 10.04 & 69.14 & 9.23 & $2.65^{*}$ & .47 \\
\hline${ }^{*} p<.05,{ }^{*} p<.01$ & & & & & \\
\hline
\end{tabular}


Table 5. Achenbach: Significance of difference between informants.

\begin{tabular}{|c|c|c|c|c|c|c|}
\hline \multirow[b]{2}{*}{ Scale } & \multicolumn{2}{|c|}{ Self } & \multicolumn{2}{|c|}{ Nominated Reporter } & \multirow[b]{2}{*}{$t$} & \multirow[b]{2}{*}{ Cohen's $d$} \\
\hline & $M$ & $S D$ & $M$ & $S D$ & & \\
\hline Anxious/Depressed & 62.79 & 10.52 & 63.64 & 8.35 & 0.60 & -- \\
\hline Withdrawn & 63.60 & 10.54 & 67.34 & 9.95 & 2.05 & -- \\
\hline Somatic Complaints & 59.51 & 10.05 & 59.15 & 9.60 & -0.32 & -- \\
\hline Thought Problems & 60.02 & 9.40 & 61.72 & 8.53 & 1.08 & -- \\
\hline Attention Problems & 61.26 & 8.20 & 63.94 & 8.52 & $2.16^{*}$ & 0.29 \\
\hline Aggressive Behavior & 56.49 & 6.64 & 56.57 & 7.35 & 0.11 & -- \\
\hline Rule-Breaking Behavior & 55.38 & 5.83 & 56.04 & 5.25 & 0.76 & -- \\
\hline Intrusive & 54.70 & 6.56 & 53.77 & 5.56 & -1.16 & -- \\
\hline Internalizing Problems & 62.00 & 12.82 & 65.15 & 9.28 & 1.93 & -- \\
\hline Externalizing Problems & 53.81 & 10.17 & 54.47 & 8.03 & 0.54 & -- \\
\hline Total Problems & 57.30 & 11.08 & 60.66 & 8.16 & $2.29 *$ & 0.35 \\
\hline Depressive Problems & 60.40 & 10.26 & 63.72 & 8.80 & $2.28 *$ & 0.35 \\
\hline Anxiety Problems & 58.45 & 7.50 & 58.70 & 8.34 & 0.21 & -- \\
\hline Somatic Problems & 59.19 & 9.60 & 58.26 & 8.92 & -0.92 & -- \\
\hline Avoidant Personality Problems & 64.06 & 10.27 & 68.19 & 8.33 & $2.88^{* *}$ & 0.44 \\
\hline AD/H Problems & 60.13 & 7.62 & 63.06 & 10.97 & 1.79 & -- \\
\hline Antisocial Personality Problems & 55.85 & 7.07 & 55.13 & 6.15 & -0.87 & -- \\
\hline
\end{tabular}

\section{Ratings of ASD symptoms}

The measure of ASD symptoms (SRS - 2) demonstrated variable inter-rater reliability between reporters. There was a significant correlation between reporters in the areas of social cognition (ICC only) and social motivation. However, in the areas of social awareness, social communication, restricted and repetitive behaviors, overall social communication, and total ASD symptoms, the ratings between individuals' self-report and nominated reporters' ratings of the individual's behavior were not significantly correlated. When examining the differences between raters, the means for all subscales of the SRS - 2 were significantly different between raters except for restricted and repetitive behaviors. On all subscales, the elected reporters rated the young adult as having significantly more symptoms of ASD when compared with the self-report. The most significant differences were found in the social communication subscale, social communication index, and in the total score. Post hoc exploratory moderator analyses did not reveal any significant demographic variables, which may have been predictive of differences in ratings of behavior between informants.

The results suggest that there is significant value in obtaining multiple ratings of most symptoms of ASD using the SRS - 2. For the majority of the SRS - 2 subscales, and for the total SRS - 2 score, the inter-informant responses were not significantly correlated, and were significantly different. This suggests separate perspectives of ASD symptoms and their impact between self- and other-reports, which together have the potential to provide a more complete profile of symptomatology for adults with ASD. Across the subscales, the results do suggest that it may be sufficient to assess social motivation and restricted and repetitive behaviors via single informant report.

Restricted interests and repetitive behaviors was the only subscale that was not significantly different between self- and other-reports. Because this subscale includes several observable, externalized behaviors, it is possible that these symptoms are easier for individuals to accurately self-evaluate. Alternatively, they are also behaviors that the individual with autism may be more likely to receive direct feedback about from others (e.g. repetitive, odd, behaviors, perseverative interests or inflexibility with routines). Similarly, initiation or desire to join certain social setting or groups may be more likely to be observed or verbally discussed (e.g., when making plans or responding to invitations) between the individual with ASD and the nominated reporter, more so than nuanced or internalized symptoms such as being able to interpret another person's feelings or facial expression accurately, or knowing if your behavior is socially "awkward" when you are trying to be polite, which are examples of symptoms represented on the social communication and social awareness scales. However, with only the self-report available, even the subscales of Restricted Interests and Repetitive Behaviors and Social Motivation should be interpreted with caution due to the bias for individuals with ASD to under-report symptoms.

\section{Ratings of comorbid psychopathology}

When examining symptoms of psychopathology, there was significant inter-rater reliability across all subscales on the Achenbach Adult Self-Report Form and Adult Behavior Checklist. There was some variability in the strength of the correlations with symptoms of withdrawal, thought problems, and Attention-Deficit/Hyperactivity symptoms demonstrating weaker associations. When comparing the means between raters, there were significant differences between raters in the areas of attention problems, depressive problems, avoidant personality problems, and total problems. No demographic variables were found post hoc to significantly predict differences between ratings of behavior. As with the SRS - 2 results above, individuals with ASD tended to report fewer symptoms as compared to the nominated reporters. However, there was less of a difference between raters than observed for ASD symptoms, as reflected in the effect sizes.

These results provide increased confidence for the utility of this instrument in young adults with ASD and support the ability for young adults with ASD to reliably self-report for the majority of comorbid symptoms of psychopathology. These results were similar to Hurtig et al. [62] who assessed inter-informant ratings of children with ASD using the child version of the Achenbach scales (Youth Self Behavior Report and the Child Behavior Checklist). They found correlations between self- and parent-report in high functioning children and adolescents with autism on nine out of 10 subscales. Ozsivadjian et al. [63] reported good inter-informant correlation on anxiety scales and 
depression scales in children with ASD and a parent, while a control group of neurotypical youth only correlated on the depression scale.

\section{Limitations}

There are a number of limitations to this study. First, all data were measured by self-report. In the future, researchers should include observational data to corroborate self- and other-report of symptoms in specifically targeted environments. As noted previously, missing data which, was excluded from the present analyses, were found to be significantly more likely for those who reported lower levels of avoidant personality problems. Therefore, it does not appear that the missing data would have impacted the findings here and would have only potentially strengthened the findings on this variable. Additionally, the sample was somewhat restricted in level of ASD impairment and ethnicity. Future research should establish whether these findings can be generalized to a wider range of impairment levels, as well as more variable ethnic backgrounds. However, there is some limitation to examining these associations in individuals with more significant ASD impairment as they may not have the ability to self-report. Finally, because these measures were completed primarily based on parental observation in the home, it is our belief that the significant correlations may be biased by shared method variance as the different informants reported on observations made in the same environment.

\section{Conclusion}

Much of the recent research and clinical interventions have focused on improving the core deficits of ASD due to the pervasive impact these deficits can have on various life domains, which continue from childhood into adulthood $[10,64]$. Difficulties in social communication, reciprocity, empathy, discriminative responding and interpretation of non-verbal or emotional states can contribute to on-going struggles with unemployment or under-employment, limited community access, and fewer opportunities for friendships and romantic relationships. These domains are critical to one's overall quality of life in adulthood, which has been reported to be significantly lower in individuals with autism $[65,66]$.

Despite the limitations, the present study expands existing knowledge of the relationship between different informants on specific behaviors in young adults with ASD. The reliability of self-reporting in individuals with ASD is increasingly important given recent data showing high prevalence of co-morbid diagnoses in adolescents and adults with autism [32-34] and the increasing need for clinicians to assess co-morbid symptoms in clinical practice [35]. While selfreported symptoms may be slightly lower when compared to otherreport, the data suggests that the Achenbach Adult Self-Report Form may be a reliable and useful source of information when treating young adults with autism.

The results suggest that when evaluating autism symptoms and severity in adults, a multi-informant approach may be necessary for an accurate and comprehensive assessment. In contrast, it may not be necessary to include ratings from both the individual themselves and an elected reporter when assessing comorbid symptoms of psychopathology in adults with ASD, if those raters are basing their ratings on the individual's behavior in one environment. As the prevalence of co-morbid psychopathology is increasingly recognized in adults with ASD, the need for reliable and efficient assessment tools for clinicians also gains importance. The results from this study may inform the future of the clinical field in regard to the use of a more efficient assessment of individuals with ASD's behavior and comorbid psychopathology symptoms in specific situations.

\section{Funding information}

This study was supported by the Bureau of Autism Services, Pennsylvania Department of Human Services Autism Services Education Resources and Training Central Pennsylvania Collaborative (PI: Murray; Co-I: Pearl). The study's findings and conclusions are those of the authors and do not necessarily represent the views of the cited funding sources.

\section{Competing interest}

The author(s) declare that they have no competing interests.

\section{References}

1. Developmental Disabilities Monitoring Network Surveillance Year \& 2010 Principa Investigators. (2014) Prevalence of autism spectrum disorder among children aged 8 years - autism and developmental disabilities monitoring network, 11 sites, United States, 2010. Morbidity and mortality weekly report.

2. American Psychiatric Association (2013) Diagnostic and statistical manual of mental Disord (5th ed.) Washington, DC.

3. Gutstein SE, Whitney T (2002) Asperger syndrome and the development of social competence. Focus on Autism and Other Developmental Disabilities 17: 161 - 171.

4. Jones EA, Carr EG (2004) Joint attention in children with autism theory and intervention. Focus on Autism and Other Developmental Disabilities 19:13 - 26.

5. Macintosh K, Dissanayake C (2006) Social skills and problem behaviours in school aged children with high-functioning autism and Asperger's Disorder. J Autism Dev Disord 36: 1065-1076. [Crossref]

6. Murdock LC, Cost HC, Tieso C (2007) Measurement of social communication skills of children with autism spectrum Disord during interactions with typical peers. Focus on Autism and Other Developmental Disabilities 22: 160 - 172.

7. Mazefsky CA, Oswald DP (2007) Emotion perception in Asperger's syndrome and high-functioning autism: the importance of diagnostic criteria and cue intensity. $J$ Autism Dev Disord 37: 1086-1095. [Crossref]

8. Demopoulos C, Brandes-Aitken AN, Desai SS, Hill SS, Antovich AD, et al. (2015) Shared and divergent auditory and tactile processing in children with autism and children with sensory processing dysfunction relative to typically developing peers. $J$ Int Neuropsychol Soc 21: 444 - 454 [Crossref]

9. Semrud-Clikeman M, Walkowiak J, Wilkinson A, Butcher B (2010) Executive functioning in children with Asperger syndrome, ADHD-combined type, ADHDpredominately inattentive type, and controls. J Autism Dev Disord 40: 1017-1027. [Crossref]

10. Otero TL, Schatz RB, Merrill AC, Bellini S (2015) Social skills training for youth with autism spectrum disorders: a follow-up. Child Adolesc Psychiatr Clin N Am 24: 99-115. [Crossref]

11. Wang P, Spillane A (2009) Evidence-based social skills interventions for children with autism: A meta-analysis. Education and Training in Developmental Disabilities 318 -342 . [Crossref]

12. White SW, Keonig K, Scahill L (2007) Social skills development in children with autism spectrum disorders: A review of the intervention research. Journal of Autism and Developmental Disord 37: 1858 - 1868. [Crossref]

13. Adams C, Green J, Gilchrist A, Cox A (2002) Conversational behaviour of children with Asperger syndrome and conduct disorder. J Child Psychol Psychiatry 43: 679690. [Crossref]

14. Baron-Cohen S, Jolliffe T, Mortimore C, Robertson M (1997) Another advanced test of theory of mind: Evidence from very high functioning adults with autism or Asperger syndrome. J Child Psychol Psychiatry 38: 813 - 822 [Crossref]

15. Klin, A (2000) Attributing social meaning to ambiguous visual stimuli in higherfunctioning autism and Asperger syndrome: The social attribution task. J Child Psychol Psychiatry 41: 831 - 846.[Crossref]

16. Magiati I, Tay XW, Howlin P (2014) Cognitive, language, social and behavioura outcomes in adults with autism spectrum disorders: a systematic review of longitudinal follow-up studies in adulthood. Clin Psychol Rev 34: 73-86. [Crossref] 
17. Constantino JN, Gruber CP (2005) Social Responsiveness Scale (SRS) Los Angeles, CA: Western Psychological Services.

18. Constantino JN, Gruber CP (2012) Social Responsiveness Scale, Second Edition (SRS -2) Torrance, CA: Western Psychological Services.

19. Constantino JN, Davis SA, Todd RD, Schindler MK, Gross MM, et al. (2003) Validation of a brief quantitative measure of autistic traits: Comparison of the Social Responsiveness Scale with the Autism Diagnostic Interview - Revised. J Autism Dev Disord 33: $427-433$ [Crossref]

20. Orsmond GI, Krauss MW, Seltzer MM (2004) Peer relationships and social and recreational activities among adolescents and adults with autism. $J$ Autism Dev Disord 34: 245-256. [Crossref]

21. Stokes M, Newton N, Kaur A (2007) Stalking, and social and romantic functioning among adolescents and adults with autism spectrum disorder. J Autism Dev Disord 37: 1969-1986. [Crossref]

22. Farley MA, McMahon WM, Fombonne E, Jenson WR, Miller J, et al. (2009) Twentyyear outcome for individuals with autism and average or near-average cognitive abilities. Autism Res 2: 109 - 118. [Crossref]

23. Howlin P (2013) Social disadvantage and exclusion: Adults with autism lag far behind in employment prospects. J Am Acad Child Adolesc Psychiatry 52: 897 - 8 [Crossref]

24. Chadsey J, Beyer S (2001) Social relationships in the workplace. Mental Retardation and Developmental Disabilities Research Reviews 7: 128 - 133.

25. Nord DK, Stancliffe R. J, Nye-Lengerman K, Hewitt AS (2016) Employment in the community for people with and without autism: A comparative analysis. Research in Autism Spectrum Disord 24: 11-16. 99.

26. Hurlbutt K, Chalmers L (2004) Employment and adults with Asperger syndrome. Focus on Autism and Other Developmental Disabilities 19: 215 - 222.

27. Mazefsky CA, Anderson R, Conner CM, Minshew N (2011) Child Behavior Checklist scores for school-aged children with autism: Preliminary evidence of patterns suggesting the need for referral. J Psychopathol Behav Assess 33: 31-37. [Crossref]

28. Leyfer OT, Folstein SE, Bacalman S, Davis NO, Dinh E, et al. (2006) Comorbid psychiatric Disord in children with autism: Interview development and rates of disorders. Journal of Autism and Developmental Disord 36: 849 - 861.

29. Joshi G, Petty C, Wozniak J, Henin A, Fried R, et al. (2010) The heavy burden of psychiatric comorbidity in youth with autism spectrum disorders: A large comparative study of a psychiatrically referred population. J Autism Dev Disord 40: 1361 - 1370. [Crossref]

30. Green J, Gilchrist A, Burton D, Cox A (2000) Social and psychiatric functioning in adolescents with Asperger syndrome compared with conduct disorder. J Autism Dev Disord 30: 279 - 293. [Crossref]

31. Mattila ML, Hurtig T, Haapsamo H, Jussila K, Kuusikko-Gauffin S, et al. (2010) Comorbid psychiatric Disord associated with Asperger syndrome/high-functioning autism: A community- and clinic-based study. J Autism Dev Disord 40: 1080 - 1093. [Crossref]

32. Lugnegård T, Hallerbäck MU, Gillberg C (2011) Psychiatry comorbidity in young adults with a clinical diagnosis of Aspergers syndrome. Res Dev Disabil 32 : 19101917. [Crossref]

33. Hofvander B, Delorme R, Chaste P, Nydén A, Wentz E, et al. (2009) Psychiatric and psychosocial problems in adults with normal-intelligence autism spectrum disorders. BMC Psychiatry 9: 1. [Crossref]

34. Joshi G, Wozniak J, Petty C, Martelon M, Fried, R et al. (2013) Psychiatric comorbidity and functioning in a clinically referred population of adults with autism spectrum disorders: A comparative study. J Autism Dev Disord 43: 1314-1325. [Crossref]

35. Matson JL, Goldin R.L (2013) Comorbidity and autism: Trends, topics and future directions. Research in Autism Spectrum Disord 7: 1228 - 1233.

36. Mayes SD, Calhoun SL, Murray MJ, Ahuja M, Smith LA (2011) Anxiety, depression, and irritability in children with autism relative to other neuropsychiatric Disord and typical development. Research in Autism Spectrum Disord 5: 474 - 485.

37. Gadke DL, McKinney C, Oliveros A (2016) Autism spectrum disorder symptoms and comorbidity in emerging adults. Child Psychiatry and Human Development 47: $194-201$.

38. Gargaro BA, Rinehart NJ, Bradshaw JL, Tonge BJ, Sheppard DM (2011) Autism and ADHD: How far have we come in the comorbidity debate? Neurosci Biobehav Rev 35 $1081-1088$. [Crossref]
39. Mayes SD, Calhoun SL, Mayes RD, Molitoris S (2012) Autism and ADHD: Overlapping and discriminating symptoms. Research in Autism Spectrum Disord 6 : $277-285$.

40. Mayes SD, Calhoun SL, Aggarwal R, Baker C, Mathapati S, et al. (2012) Explosive, oppositional, and aggressive behavior in children with autism compared to other clinical Disord and typical evelopment. Research in Autism Spectrum Disord 6: 1-10.

41. Simonoff E, Pickles A, Charman T, Chandler S, Loucas T, et al. (2008) Psychiatric Disord in children with autism spectrum disorders: Prevalence, comorbidity, and associated factors in a population-derived sample. J Am Acad Child Adolesc Psychiatry 47: $921-929$. [Crossref]

42. Achenbach TM, Krukowski RA, Dumenci L, Ivanova MY (2005) Assessment of adult psychopathology: Meta-analyses and implications of cross-informant correlations. Psychol Bull 131: 361 - 382. [Crossref]

43. Achenbach TM (2006) As others see us: Clinical and research implications of crossinformant correlations for psychopathology. Current Directions in Psychological Science 15: $94-98$

44. Baron-Cohen S, Wheelwright S, Skinner R, Martin J, Clubley E (2001) The AutismSpectrum Quotient (AQ): Evidence from Asperger Syndrome/ high-functioning autism, males and females, scientists and mathematicians. Journal of Autism and Developmental Disorders: 31: 5-17.

45. Hurley RS1, Losh M, Parlier M, Reznick JS, Piven J (2007) The broad autism phenotype questionnaire. J Autism Dev Disord 37: 1679-1690. [Crossref]

46. Koning C, Magill-Evans J (2001) Validation of the child and adolescent social perception Measure. OTJR: Occupation, Participation and Health 21: 49-67.

47. Knott F, Dunlop AW, Mackay T (2006) Living with ASD: how do children and their parents assess their difficulties with social interaction and understanding? Autism 10 609-617. [Crossref]

48. Johnson SA, Filliter JH, Murphy RR (2009) Discrepancies between self- and parentperceptions of autistic traits and empathy in high functioning children and adolescents on the autism spectrum. J Autism Dev Disord 39: 1706-1714. [Crossref]

49. De la Marche W, Noens I, Kuppens S, Spilt JL, Boets B, et al. (2015) Measuring quantitative autism traits in families: informant effect or intergenerational transmission? Eur Child Adolesc Psychiatry 24: 385-395. [Crossref]

50. Pearl AM, Murray MJ, Smith LA, Arnold M (2013) Assessing adolescent social competence using the Social Responsiveness Scale: Should we ask both parents or will just one do? Autism 17: 736 - 742 .

51. Posserud MB, Lundervold AJ, Gillberg C (2006) Autistic features in a total population of 7 - 9-year-old children assessed by the ASSQ (Autism Spectrum Screening Questionnaire). J Child Psychol Psychiatry 47: 167 - 175. [Crossref]

52. Achenbach TM, McConaughy SH, Howell CT (1987) Child/adolescent behavioral and emotional problems: Implications of cross-informant correlations for situational specificity. Psychol Bull 101:213. [Crossref]

53. De Los Reyes A, Kazdin AE. (2005) Informant discrepancies in the assessment of childhood psychopathology: A critical review, theoretical framework, and recommendations for further study. Psychol Bull 131: 483. [Crossref]

54. Duhig AM, Renk K, Epstein MK, Phares, V. (2000) Interparental agreement on internalizing, externalizing, and total behavior problems: A meta-analysis. Clinical Psychology: Science and Practice 7: 435 - 453.

55. Moreno J, Silverman WK, Saavedra LM, Phares V (2008) Fathers' ratings in the assessment of their child's anxiety symptoms: A comparison to mothers' ratings and their associations with paternal symptomatology. J Fam Psychol 22: 915. [Crossref]

56. Schroeder JF, Hood MM, Hughes HM. (2010) Inter-parent agreement on the syndrome scales of the Child Behavior Checklist (CBCL): Correspondence and discrepancies. Journal of Child and Family Studies 19: 646 - 653.

57. Bonifacci P1 (2004) Children with low motor ability have lower visual-motor integration ability but unaffected perceptual skills. Hum Mov Sci 23: 157-168. [Crossref]

58. Achenbach TM, Rescorla LA. (2003) Manual for the ASEBA adult forms \& profiles. Burlington, VT University of Vermont, Research Center for Children, Youth and Families.

59. Frazier TW, Ratliff KR, Gruber C, Zhang Y, Law PA, et al. (2014) Confirmatory factor analytic structure and measurement invariance of quantitative autistic traits measured by the Social Responsiveness Scale - 2. Autism 18: 31 - 44. [Crossref]

60. Curan PJ, West SG, Finch JF (1996) The robustness of test statistics to nonnormality and specifictation error in confirmatory factory analysis. Psychological Methods 1: 16 
Pearl AM (2016) Comparison of self-and other-report of symptoms of autism and comorbid psychopathology in adults with autism spectrum disorder

61. Hoyle RH (1995). Structural Equation Modeling: Concepts, issues and applications. Sage Publications.

62. Hurtig T, Kuusikko S, Mattila M, Haapsamo H, Ebeling H, et al. (2009) Multiinformant reports of psychiatric symptoms among high-fucntioning adolescents with Asperger syndrome or autism. Autism 13: 583-598.

63. Ozsivadjian A, Hibberd C, Hollocks MJ (2014) Brief Report: The use of self-report measures in young people with autism spectrum disorder to access symptoms of anxiety, depression and negative thoughts. J Autism Dev Disord 44: 969-974. [Crossref]
64. Rao PA, Beidel DC, Murray MJ. Social skills interventions for children with Asperger's syndrome or high-functioning autism: A review and recommendations. $J$ Autism Dev Disord 38: 353 - 361.[Crossref]

65. Jennes-Coussens M, Magill-Evans J, Koning C (2006) The quality of life of young men with Asperger syndrome: a brief report. Autism 10: 403-414. [Crossref]

66. Wing L, Schopler E, Mesibov GB (1983) Social and interpersonal needs. Autism in Adolescents and Adults Plemun Press New York. 337 - 354

Copyright: $\odot 2016$ Pearl AM. This is an open-access article distributed under the terms of the Creative Commons Attribution License, which permits unrestricted use, distribution, and reproduction in any medium, provided the original author and source are credited. 